\title{
NOTAS SOBRE LA FAMILIA LORANTHACEAE Y EL PARASITISMO SECUNDARIO
}

Ramón Riba*

Al observar el modo de vida de las plantas fanerógamas, encontramos algunas familias cuyos miembros en su totalidad o en parte son de hábitos parasíticos o hemiparasíticos, es decir, se alimentan total o parcialmente de substancias orgánicas elaboradas previamente por el hospedero, o absorben agua y sales minerales del mismo además de substancias orgánicas.

Entre ellas están las raflesiáceas y orobancáceas que parasitan raíces de algunos árboles cercanas a la superficie (Orobanche); las santaláceas con algunas especies parásitas de raíces y ramas de árboles (Comandra); las convolvuláceas, con la bien conocida Cuscuta; las escrofulariáceas con el género Hyobanche, desprovista de clorofila, y por último, la familia que nos ocupará en adelante, las lorantáceas cuyos miembros, con dos excepciones (Nuytsia, Gaiadendron), son parásitos de ramas de árboles y arbustos.

Los miembros de esta familia tienen tallos generalmente ramificados en forma dicótoma, con nudos casi siempre hinchados; las hojas son persistentes y coriáceas, opuestas o verticiladas, rara vez alternas, simples, enteras y de color verde o amarillento; a veces las hojas se reducen a escamas como en el género Arceuthobium; las flores son solitarias, paniculadas o en espigas, hermafroditas o unisexuales, siendo en este caso dióicas; actinomorfas, verdes a amarillento rojizo o rojo; perianto biseriado (Psittacanthus); son generalmente trímeras. Los estambres son en igual número que los segmentos del perianto; las anteras tienen dos sacos polínicos, dehiscentes longitudinalmente por hendeduras transversales o por poros terminales; el ovario es ínfero, embebido en el receptáculo floral; estilo sencillo o ausente; el estigma es único, a menudo sésil. El fruto es una baya o drupa con dos a tres semillas, viscoso.

Esta familia se distingue de las demás, porque sus miembros, con las excepciones antes citadas son de hábito aéreo parasítico, receptáculo floral en forma de copa y ovario ínfero que carece de un lóculo claramente definido.

Encontramos en esta familia dos grandes grupos bien diferenciados, la subfamilia Loranthoidea (Struthanthus, Psittacanthus), caracterizada por la presencia de un anillo ligeramente dentado por debajo del perianto llamado calículo y la subfamilia Viscoidea (Phoradendron) que carece de este calículo.

Hasta donde sabemos, las especies de hábito parasítico no atacan helechos arbóreos ni monocotiledóneas, y relativamente pocas son encontradas en coníferas (Phoradendron juniperinum Engelm.).

* Instituto de Biología, U.N.A.M.

Riba R. 1963. Notas sobre la familia Loranthaceae y el parasitismo secundario. Boletín de la Sociedad Botánica de México 28: 1-9. 
Aunque en ocasiones se encuentran sobre hospederos no relacionados entre sí, existen muchas especies que tienen cierta selectividad hacia la planta atacada. Las coniferas, que son parasitadas en gran proporción por los géneros Arceuthobium y Razoumofskya, parecen ser parasitadas solamente por un cierto número de especies de Phoradendron, que constituyen un grupo bien limitado, Pauciflorae, restringido a coníferas excepto $P h$. californicum Nutt. que afecta a muchas angiospermas, pero no gimnospermas y Ph. bolleanum (Seem.) Eichler, de Chihuahua, que se ha colectado sobre Arbutus además de sobre coníferas.

Esta familia la forman 30 géneros y aproximadamente 1100 especies que están distribuidas en el globo terrestre en una faja que tiene sus límites al norte y sur del ecuador correspondiendo aproximadamente con los de las regiones templadas de ambos hemisferios.

En México la familia está 'representada por ocho géneros distribuidos como sigue:

Phoradendron, en tocio el país con aproximadamente 80 especies.

Struthanthus, también en todo el país con 12 especies.

Psittacanthus, con 7 especies, en la parte central, sur y sureste de la República.

Phrygilanthus, con dos especies, en Baja California, Sonora, Chihuahua, Jalisco y Puebla.

Arceuthobium, con una especie en Baja California y una en la parte central.

Oryctanthus, con una especie en Chiapas.

Razoumofskya, en Sonora, Coahuila y Oaxaca con una especie.

Antidaphne, con una especie en Chiapas.

La alimentación de las lorantáceas, con las excepciones mencionadas en un principio, se lleva a cabo mediante órganos especiales llamados haustorios. discos chupadores o discos adhesivos, interpretados generalmente como raíces modificadas, ya que mediante ellas las lorantáceas absorben substancias nutritivas de la planta parasitada. En este momento cabe hacer la aclaración de que las lorantáceas no cárecen de clorofila, pudiendo por tanto sintetizar compuestos orgánicos, por lo que se les debe considerar más apropiadamente como plantas hemiparásitas.

Los discos adhesivos a que antes se hizo referencia pueden ser únicos como en los géneros Phoradendron y Psittacanthus, o pueden formarse en los distintos lugares en los que se pone en contacto el tallo de la hemiparásita con el tallo de la planta hospedera, como en las especies del género Struthanthus. En uno o en otro caso se puede distinguir, al hacer un corte del lugar 
donde el disco se adhiere a la rama, que los hacecillos conductores del hemiparásito se introducen en el tejido del hospedero, poniéndose en contacto con los de éste (Fig. 1). El disco adhesivo de las especies del género Psittacanthus especialmente, produce en el sitio de adherencia a la rama del hospedero una hipertrofia de la misma, en la que al desprenderse el disco y desintegrarse el tejido restante, se observa que se han desarrollado una serie de costillas más o menos radiales que le dan un atractivo aspecto conociéndoseles popularmente como "flores de madera". El tamaño de estas flores de madera depende de la edad alcanzada por el hemiparásito, y puede después de algunos años alcanzar un diámetro de 70 centímetros. Todavía en vida del hemiparásito, la masa porosa central del disco puede ser invadida por insectos, principalmente hormigas, que viven en su interior y pueden ser causantes del desprendimiento del hemiparásito por debilitamiento del disco.

Concretando, los efectos que los hemiparásitos pueden provocar a los hospederos pueden ser los siguientes:

1) Pueden extraer suficiente agua y sales minerales que dejan a la parte distal de la rama del hospedero sin posibilidad de desarrollo.

2) La presencia del hemiparásito puede estimular el crecimiento local de las 'regiones afectadas del hospedero, produciéndole enormes deformidades locales, como es el caso de las "flores de madera".

3) Los productos de excreción del hemiparásito pueden actuar como toxinas sobre el hospedero, matándolo por completo o impidiéndole crecimiento posterior.

A pesar de su hábito hemiparasítico las lorantáceas no están a salvo de ser invadidas ya sea por verdaderos parásitos, como es el caso citado por Trelease (6) en su revisión del género Phoradendron, de un ejemplar de $P h$. antillarum Trel., parasitado por Cuscuta sp., o bien por hemiparásitos de la misma familia. Respecto a esto último, únicamente tenemos datos sobre el grupo Amplectentes, formado por especies tropicales de Phoradendron entre las que podemos citar Ph. casimiranum Trel. de Brasil y Paraguay, Ph. tetrapterum (Krug. \& Urban) Trel. de las Antillas y el Caribe, Ph. demerarae Trel. de las Guayanas y Ph. amplectens Trel. del Ecuador. Estas cuatro especies están localizadas únicamente en la América del Sur y viven exclusivamente sobre otras especies de lorantácas.

Buscando más datos al respecto, no hemos encontrado reportes acerca de si otros géneros de la misma familia o especies distintas de Phoradendron son parasitados o parasitan otras especies de lorantáceas. Sin embargo, en excursiones de colecta a distintas partes del país del año 1958 a la fecha, se han encontrado tres casos de parasitismo o hemiparasitismo secundario entre miem. bros de la misma familia, interesantes a nuestro modo de ver porque nos per- 
miten apreciar que no existe selectividad de la planta invasora hacia la planta hospedera, como se verá más adelante.

El primer caso es el encontrado en los alrededores de Chiapa de Corzo, estado de Chiapas, en un ejemplar de Acacia pennatula (Schlecht. \& Cham.) Benth. ("cuquet"), con una de sus ramas invadida por Psittacanthus calyculatus (D. C.) Don. con la consiguiente hipertrofia de la zona afectada de la rama. A unos cuarenta centímetros del disco, las ramas de Psittacanthus presentaban la inserción de un ejemplar femenino de Phoradendron tamaulipense Trel., del grupo Quadrangulares, ya con fruto, es decir, completamente desarrollado sobre el Psittacanthus. En ninguna de las dos plantas encontramos muestras de degeneración producida por el parasitismo secundario, a no ser el ligero engrosamiento producido en Psittaconthus en el lugar de inserción de Phoradendron, si bien este engrosamiento era mucho menor que los producidos ordinariamente por especies de este último género.

El segundo de ellos fue encontrado a la altura del kilómetro 610 de la carretera Panamericana, a $65 \mathrm{~km}$. de Oaxaca; un ejemplar de Quercus oleoides Cham. \& Schlecht. estaba invadido por un Pharadendron robusto, envuelto junto con las ramitas anexas del encino por una maraña, al parecer de algún bejuco, el que al examinarlo de cerca se identificó como Struthanthus. Al ser exáminados en el herbario fueron identificados como Phoradendron purpusi Trel. del grupo Nervosae, de México y considerada como hemiparásita exclusivamente de Quercus spp., y el otro como Struthanthus haenkeanus (Presl.) Standl. Los lugares de inserción de las dos especies sobre el encino estaban separados entre sí unos 40 ó 50 centímetros, pero de ahí, el ejemplar de Struthanthus se enredaba en las ramas delgadas del encino mediante pequeños haustórios; al alcanzar las ramas de Phoradendron purpusi Trel. se adhería a ellas de tal manera que los hacecillos conductores de los haustorios llegaban hasta el interior de la rama del muérdago (figs. 2 y 3 ). A pesar de esto, las ramas afectadas de Phoradendron no mostraban variación alguna en cuanto a color, robustez y aspecto general, es decir, no presentaba alteraciones debidas al hemiparásito.

El último de los ejemplares fue localizado sobre la carretera a Tuxpan, Ver., en los alrededores de Huauchinango, Pue., en un encinar de Quercus glauccides Mart. \& Gal.; en esta zona abunda sobremanera Phoradendron carneum Urban, atacando a gran cantidad de encinos, así como Ph. cályculatum Trel. aunque éste en menor número, seguidos en frecuencia por Struthanthus densiflorus (Bent.) Standl. Un ejemplar de Quercus glaucoides Mart. \& Gal., estaba fuertemente atacado por Struthanthus densiflorus Benth. \& Standl. a tal grado que los tallos de este último alcanzaban diámeros desusados de 1.5 a 2 centímetros. Precisamente sobre uno de los tallos de mayor grosor se encontraron varias inserciones de Phoradendron el que fue identificado como $P h$. 
calyculatum Trel. del grupo Alatae de las montañas del centro de México, a pesar de ser brotes jóvenes o alterados, ya que los entrenudos eran más cortos y robustos de lo normal en esta especie y las hojas estaban algo atrofiadas, de menor tamaño y curvadas sobre sí mismas. Los lugares de inserción presentaban-los hinchamientos característicos de Phoradendron y la unión entre las dos plantas estaba perfectamente establecida. (fig. 4).

Conclusione.j.-La invasión de Psittacanthus calyculatus (D. C.) Don., Phoradendron purpusi Trel. y Struthanthus densiflorus por las tres especies de lorantáceas mencionadas al respecto, nos hacen ver que aunque existe cierta selectividad hacia el hospedero, la presentan grupos muy reducidos, p. e. los grupos Pauciflorae y Amplectentes del género Phoradendron, que invaden coníferas y lorantáceas respectivamente, aunque en el primero de ellos esta selectividad aparente, acaso se deba a la abundancia de coníferas en los lugares de colecta, en relación con la escasez de otras especies arbóreas en los bosques de ese tipo.

Ahora bien, en los dos casos de parasitismo secundario presentados por Psittacanthus calyculatus y Struthanthus densiflorus parasitados por Phoradendron tamaulipense y Phoradendron calyculatum, este fenómeno está relacionado con la existencia de estas últimas especies directamente sobre los árboles de la región, y la consecuente abundancia de las semillas que debido a su cubierta viscosa, pueden haberse adherido fácilmente a los tallos de las plantas atacadas.

En el caso de la invasión de Phoradendron purpusi por Struthanthus haenkeanus, por no estar el punto primario de inserción de Struthanthus sobre Phoradendron, sino sobre el encino, la adhesión puede haberse debido meramente a una contigüidad de las ramas de uno y otro, ya que en la zona de colecta, no se encontró ningún ejemplar de Struthanthus con su punto primario de inserción sobre Phoradendron, sino solamente sobre Quercus oleoides.

\section{REFERENCIAS BIBLIOGRAFICAS}

1.-Core, E. T. 1955. Plant Taxonomy. Prentice Hall, Inc.

2.-Hedgcock, G. G. 1915. Notes on some diseases of trees in our National Forests. Phytopathology, Vol. 5, 175-181.

3.-Lawrence, G.H.M. 1951 Taxonomy of Vascular Plants. The MacMillan Company, New York.

4.-Stand'ey, P. C. 1922. Trees and Shrubs of Mexico. Contributions from the U. S. National Herbarium. XXIII-2, 222-235.

5.-Standley, P. C. 1937. Flora of Costa Rica. Field Columbian Museum. XVIII-2, 402-408.

6.-Trelease, W. The Genus Phoradendron. A Monographic Revision. Urbana, Illinois. 1916. 


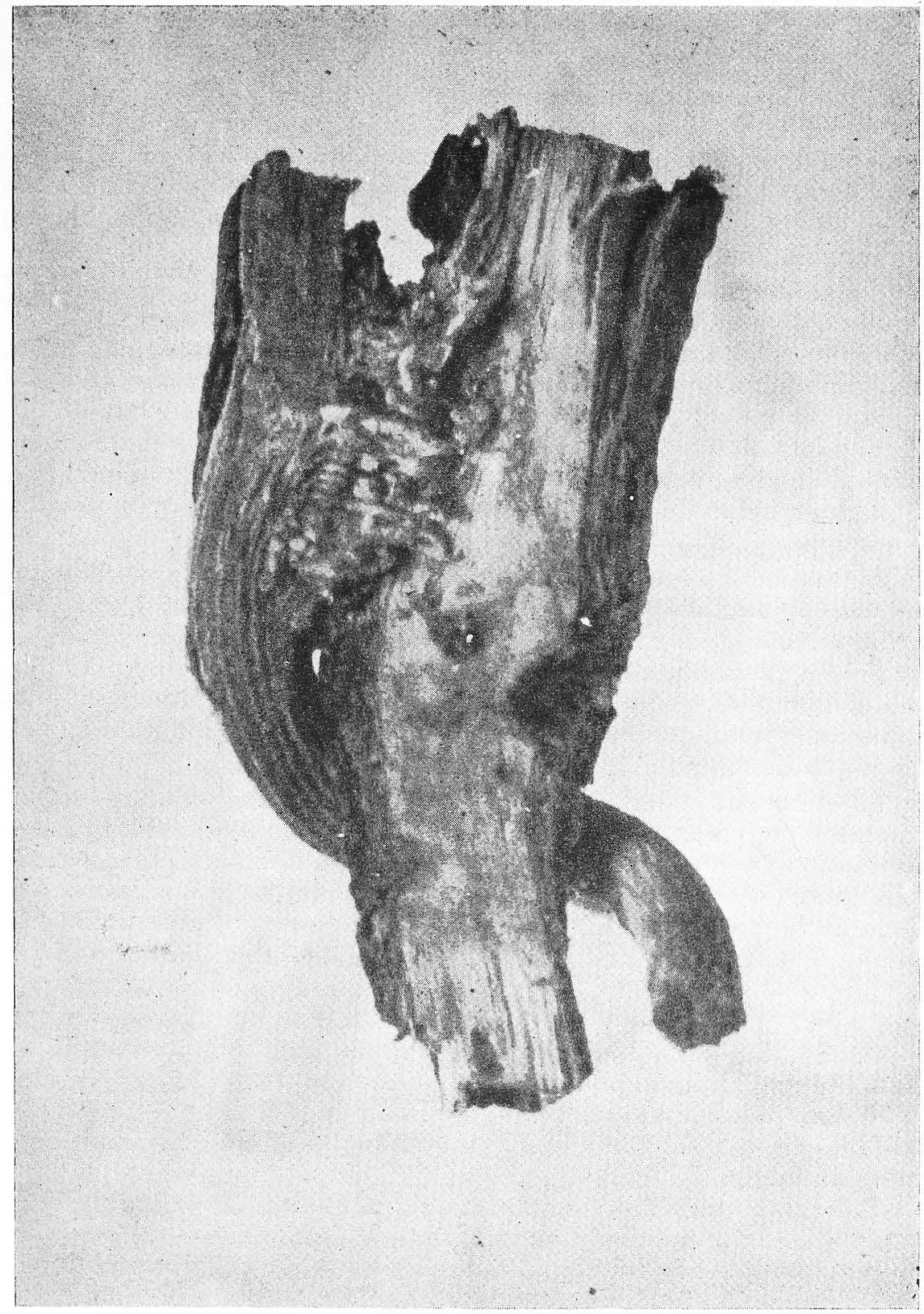

Fig. 1.- Inserción de un haustorio de S. haenkeanus sobre una rama de Quercus oleoides. (corte) 




Fig. 2.- Inserción de los haustorios de $\mathbf{S}$. haenkeanus sobre las ramas de Ph. purpusi. 


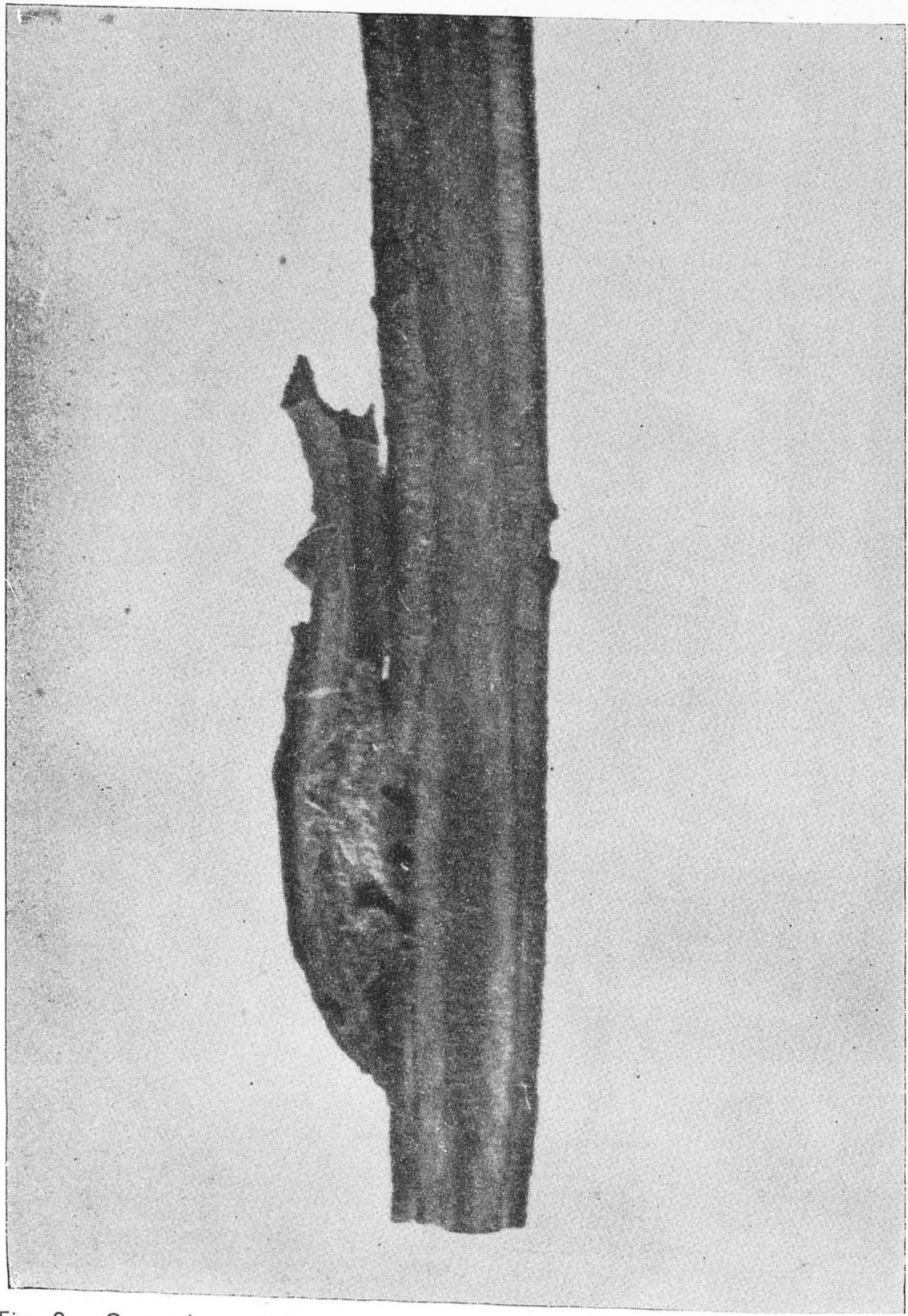

Fig. 3.-Corte de un haustorio de S. haenkeanus implantado en una rama de Ph. purpusi. 

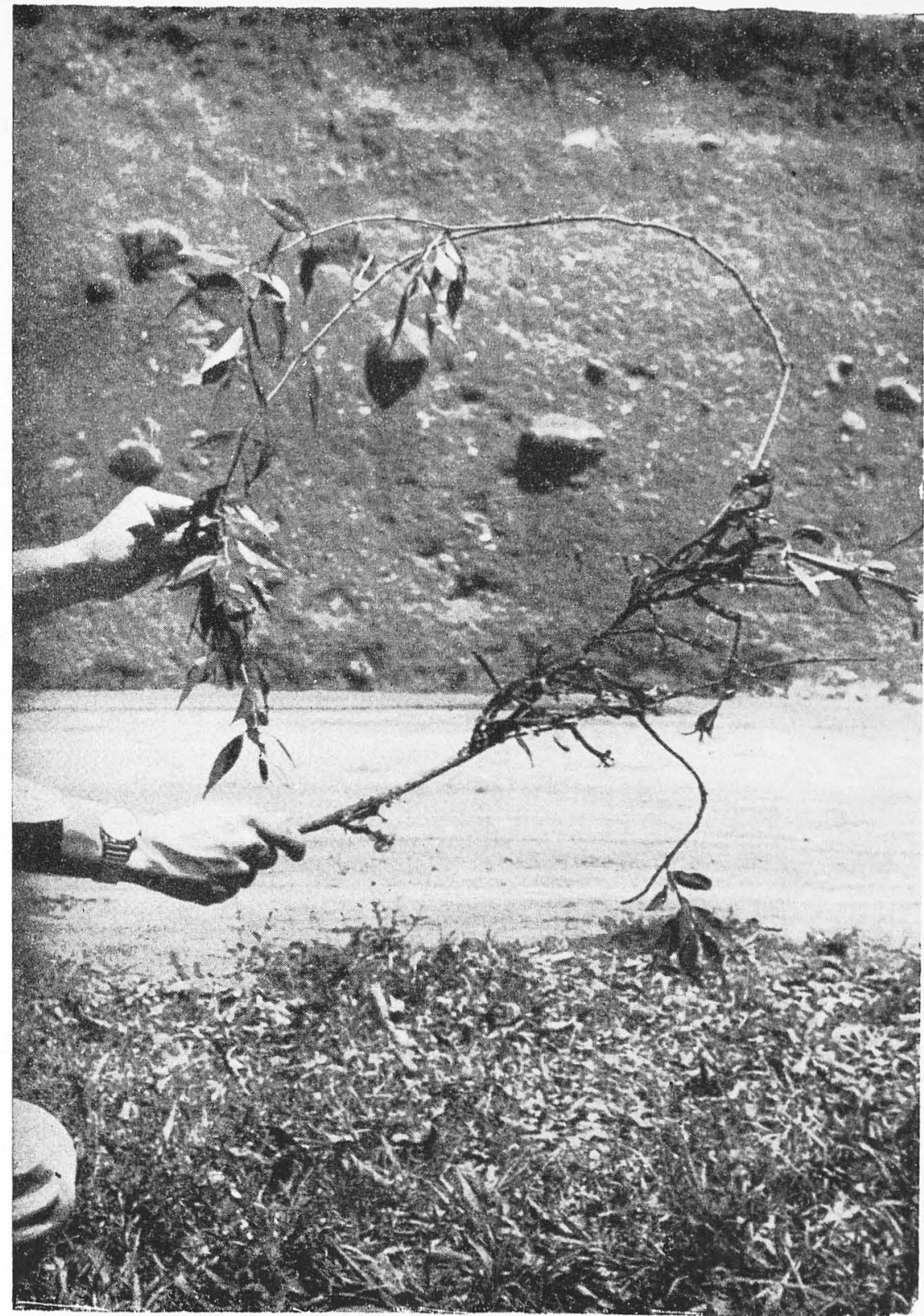

Fig. 4.-Asociación entre Ph. calyculatum sobre S. densiflorus. 